\title{
Correction to: The estimation of influencing factors for carbon emissions based on EKC hypothesis and STIRPAT model: Evidence from top 10 countries
}

\author{
Ellen Thio ${ }^{1}$ MeiXuen Tan ${ }^{1} \cdot{\text { Liang } \mathrm{Li}^{1,2} \text { (D) } \cdot \text { Muhammad Salman }}^{3} \cdot$ Xingle Long $^{4}$. \\ Huaping Sun ${ }^{5} \cdot$ Bangzhu Zhu ${ }^{1}$
}

Published online: 2 March 2022

(c) Springer Nature B.V. 2022

\section{Correction to: Environment, Development and Sustainability https://doi.org/10.1007/s10668-021-01905-z}

Unfortunately, in the original publication of the article [1], the sentence "The results obtained show that firstly, the main results are that income per capita significantly increases environmental pollution across top 10 carbon emissions countries; this study also supported the EKC hypothesis in the top 10 countries in China, USA, India, Russia, Japan,

The original article can be found online at https://doi.org/10.1007/s10668-021-01905-z.

\author{
Liang Li \\ 1lcwllcw@hotmail.com \\ Ellen Thio \\ thio_ellen@yahoo.com \\ MeiXuen Tan \\ mathevas93@hotmail.com \\ Muhammad Salman \\ dawarsalman@gmail.com \\ Xingle Long \\ longxingle@163.com \\ Huaping Sun \\ shp797@163.com \\ Bangzhu Zhu \\ wpzbz@126.com
}

1 School of Business, Nanjing University of Information Science and Technology, Nanjing 210044, China

2 Research Institute for Environment and Health, Nanjing University of Information Science and Technology, Nanjing 210044, China

3 College of Economic and Management, Nanjing University of Aeronautics and Astronautics, Nanjing 211106, China

4 School of Management, Jiangsu University, Zhenjiang 212013, China

5 School of Finance and Economics, Jiangsu University, Zhenjiang 212013, China 
Germany, South Korea, Canada, Mexico, and South Africa in China, USA, India, Russia, Japan, Germany, South Korea, Canada, Mexico, and South Africa" appearing in abstract contains the country name twice.

The correct sentence is "The results obtained show that firstly, the main results are that income per capita significantly increases environmental pollution across top 10 carbon emissions countries; this study also supported the EKC hypothesis in the top 10 countries in China, USA, India, Russia, Japan, Germany, South Korea, Canada, Mexico, and South Africa."

Publisher's Note Springer Nature remains neutral with regard to jurisdictional claims in published maps and institutional affiliations. 